\title{
SIMMONDS' DISEASE
}

\author{
With Reports of Four Cases
}

\author{
By F. W. WolfF, M.B., B.S.(Dunelm) \\ Medical Registrar, Southend General Hospital
}

Since Simmonds' (1914) original description, the concept of this disease has untlergone a considerable change. The subject has recently been brilliantly reviewed by Sheehan and Summers (1949). The severe wasting originally described is now known to be a relatively infrequent presenting feature of the disease. It appears that many of the middle-aged, adequately nourished women with tired, immobile, pale faces apt to be diagnosed variously as myxoedema, premature menopause, chronic anaemia, vitamin deficiency or merely debility and exhaustion, are in reality suffering from a major or minor degree of hypopituitarism.

Of the four cases under review, the first was correctly diagnosed only after death, when lengthy out-patient notes were correlated with the post-mortem findings. The second was treated as a case of 'nutritional anaemia,' and only incompletely investigated; grounds will be given for the diagnosis. Cases 3 and 4 were recognized as suffering from the condition at an early stage and were further investigated.

Case I. A married woman of 47 was admitted in coma on 6.9.49 and died within six hours of admission without regaining consciousness. She had not been well since a difficult confinement with severe post-partum haemorrhage in 1927. After a further pregnancy in 1935 she had a second post-partum haemorrhage, since when her outpatient notes significantly described her as 'exhausted.' She was shown to have an achlorhydria with a microcytic anaemia. After a high colour index report in 1943 she was given liver extracts. From that time she was kept on crude liver extracts, iron, vitamins and eventually folic acid. Little improvement resulted. Her haemoglobin varied between 60 and 70 per cent., but it appears clear that her debility, weakness and anaemia were due to factors other than bone marrow deficiency. In July 1949 the out-patient notes contain the following entry:- 'Haemoglobin 55 per cent. Feels sleepy, always cold, loss of hair marked, all movements slow and deliberate, ? myxoedema '; and a week later another entry:'Blood cholesterol 195 mgm. per cent., no response to therapy. Suggest bone marrow is exhausted. Should be admitted for blood transfusion.'

On 6.9.49 she was admitted in coma. The immediate story was that four days previously she had felt extremely weak; on the following day she had been sick several times and her speech had become confused. She collapsed on the morning of admission.

On admission she was pale, cold and shocked. Axillary and pubic hair were absent. The pulse was of very poor volume, rate 35 ; blood pressure, systolic 55, diastolic unobtainable. Her lungs showed signs of basal congestion. Both plantar responses were extensor, no other abnormal signs being found in the central nervous system. A provisional diagnosis of either cerebral thrombosis or phenobarbitone poisoning was made. Lumbar puncture gave normal results in all respects; the urine contained no barbiturates, whilst the haemoglobin was 64 per cent. Six hours after admission the patient died in coma. A post-mortem was performed. The relevant findings were that all the internal organs were small and much underweight, particularly the suprarenal and thyroid glands. The pituitary gland was not examined.

Case 2. A married woman aged 57 came under observation in May 1949. In 1920 she had had her last pregnancy, followed by a severe postpartum haemorrhage. Since that time she had complained of tiredness, weakness, shortness of breath, anorexia and amenorrhoea. She had been treated at varying times with iron and blood transfusions. On admission she was pale and poorly nourished. The skin was dry and inelastic. Axillary and pubic hair were completely absent, a condition which she dated from the birth of her last child 29 years previously. The pulse rate was 60 and the rhythm regular; blood pressure 120/75. No other abnormal physical signs were found.

Investigations: Chest X-ray normal. Glucose tolerance curve: Fasting blood sugar $56 \mathrm{mgm}$. per cent., rising after glucose slowly to I44 mgm. per cent. Serum cholesterol: $302 \mathrm{mgm}$. per cent. Seventeen ketosteroid excretion in 24 hours: 3 mgm. X-ray of sella turcica normal. Haemo- 


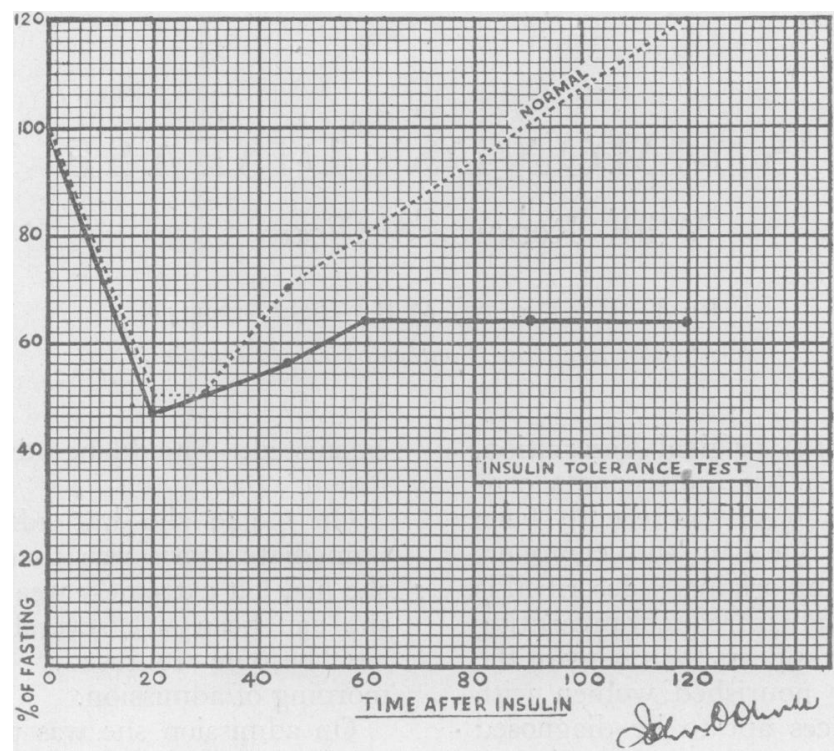

Fig. I.

globin 90 per cent. Fractional test meal normal. Since discharge the patient has been given thyroid extract gr. $\frac{1}{2}$ b.d. and methyl testosterone mgm. Io t.d.s. She was last seen in February I950 and has made a remarkable objective and subjective improvement. Not only has the anaemia been corrected, but for the first time for many years she feels well and has, as she says, ' plenty of energy.' She is brighter and more cheerful. Her scalp hair is less dry and more plentiful, but there has been no regrowth of axillary or pubic hair.

Case 3. A woman of $4 \mathrm{I}$ nine years previously had had a difficult delivery with a massive postpartum haemorrhage. She had 'never pulled round since,' had complained of lack of energy, tiredness, cold hands and 'anaemia,' and had noticed loss of axillary and pubic hair. She had had amenorrhea since the haemorrhage, with only one bleeding in February 1949. All her movements as well as her speech had gradually become slower.

On Admission (19.7.49) she was heavily built with pale, smooth skin, the facies immediately suggesting a diagnosis of myxoedema. The voice was slow and croaking. Axillary and pubic hair were absent. The tongue was large and smooth. There were no supraclavicular pads of fat and no loss of hair at the outer canthus. Pulse rate 70 ; blood pressure $120 / 70$. No other abnormal signs were found.

Investigations:-Blood cholesterol: $430 \mathrm{mgm}$. per cent. Basal metabolic rate: minus 40 . Electrocardiogram: Inversion of $\mathrm{T}$ wave in all three limb leads, as in the typical 'myxoedema heart.' Fasting blood sugar: $80 \mathrm{mgm}$. per cent. X-ray skull: normal. Seventeen ketosteroids: 9.9 mgrm. per 24 hours.

The insulin tolerance test result (Frazer an Smith, I94I), using O.I units per $\mathrm{kg}$. body weig intravenously, is shown in Fig. I. The test was accompanied by severe hypoglycaemic symptoms, the blood pressure falling to $80 / 60$.

A diagnosis of hypopituitarism with pre-气ू

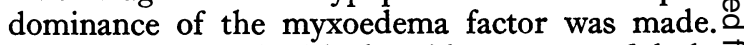

She was treated with thyroid extract gr. $\frac{1}{2}$ b.d., $\overrightarrow{\vec{B}}$ which was later increased to gr. I b.d., and she $\exists$ was discharged on 6.8.49.

As an out-patient, on 18.8.49 she looked very? ill. She said she had been feeling weak and hado been vomiting repeatedly. She had lost ro $1 \mathrm{~b} .3$ weight in 12 days. The haemoglobin was 62 per cent.; blood cholesterol 164 mgm.; plasmasodium $322 \mathrm{mgm}$; and plasma potassium $16.8 \mathrm{O}$ mgm. per cent. It was clear that the treatment had almost succeeded in producing an Addisonian? crisis.

Thyroid therapy was therefore omitted and replaced by methyl testosterone mgm. 1o t.d.N From September I949 to March 1950 she remained ${ }_{N}$ on this treatment with marked subjective and someo objective improvement. She felt better, had more energy, could do her housework and even take long walks, which she had been unable to do fore years. Her voice was also returning to normal

This improvement was accompanied by $a$ marked rise in her plasma cholesterol, which on I0.2.50 was $743 \mathrm{mgm}$. per cent. 


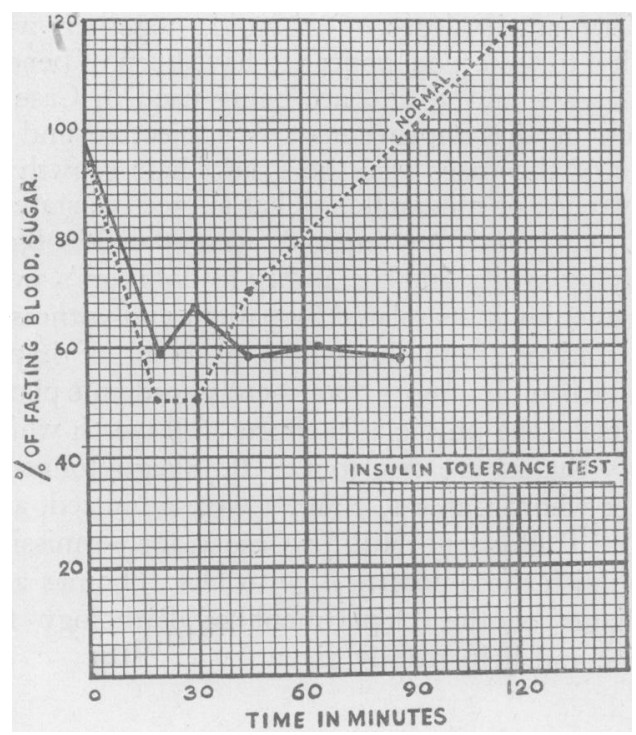

FIG. 2.

In March $195^{\circ}$ she was readmitted to hospital for further investigation. The blood cholesterol was then $450 \mathrm{mgm}$. per cent. and the basal metabolic rate plus $2 \mathrm{I}$. The insulin sensitivity test was typical of Simmonds' disease, the glucose level falling to $33 \mathrm{mgm}$. per cent. The eosinophil test (Thorn, I949) was performed and, 4 hours after the administration of $0.1 \mathrm{ml}$. I:I000 adrenaline, there was a fall of only is per cent. in the total eosinophil count, a finding in accordance with adrenal pituitary deficiency. Whilst in hospital, thyraid extract was cautiously given again, gr. $\frac{1}{4}$ b.d., rising for a time to gr. $\frac{1}{2}$ b.d. However, even with this small dose she showed signs of intolerance, with nausea, faintness and $4 \mathrm{lb}$. weight loss in one week. Eventually she was discharged in good condition on thyroid gr. $\frac{1}{4}$ b.d., her blood cholesterol on discharge being 439 mgm. per cent.

Case 4. In 1944 a woman of $4 \mathrm{I}$, whilst in her eighth month of pregnancy was involved in a $\mathrm{V}$-bomb incident, losing the child and having a severe post-partum haemorrhage. Since that time there had been a slow and steady deterioration in her condition, with lethargy, weakness and, in the past two years, occasional vomiting. She did not think she had lost weight. Her periods since the haemorrhage had been scanty and occurred only about every five months. She herself had noticed the loss of her axillary hair and stated that her head hair had become coarse and brittle. She felt the cold badly and was often constipated. She had had in all six pregnancies.

On admission (31.3.50) she was small and thin. Speech was slow and the extremities cold. The face was small and pointed, and the skin had a peculiar pale, waxen, smooth appearance. Axillary and pubic hair were absent. Nails were normal. Pulse rate was 6o, and regular; blood pressure 90/50. No other abnormal physical signs were discovered.

Investigations:-Basal metabolic rate: 50 per cent. Blood cholesterol: $505 \mathrm{mgm}$. Haemoglobin: 69 per cent. Fractional test meal: normal. Fasting blood sugar: $65 \mathrm{mgm}$. Blood sodium: $300 \mathrm{mgm}$. Blood potassium: $20 \mathrm{mgm}$. per cent. Seventeen ketosteroids in 24 hours : $7.2 \mathrm{mgm}$.

An insulin sensitivity test was performed (Fig. 2). In view of her hypotension she was given only the smaller testing dose, i.e. 0.03 units insulin per $\mathrm{kg}$. of body weight. Even with the smaller dose she went into a very severe hypoglycaemic state, the systolic blood pressure dropping to $50 \mathrm{~mm}$. of $\mathrm{Hg}$ and, two hours after it was started, the test was abandoned. The patient, when given $40 \mathrm{gm}$. of glucose by mouth and $0.5 \mathrm{ml}$. I : I000 adrenaline intramuscularly, recovered promptly. As can be seen, the curve shows marked insulin sensitivity.

An eosinophil test was performed and showed a fall of only 29 per cent. in total eosinophils 4 hours after injection, again in keeping with hypopituitarism or adrenal deficiency.

She is now under treatment as an out-patient with thyroid gr. $\frac{1}{4}$ b.d. and methyl testosterone.

\section{Summary and Comment}

Four cases of hypoptituitarism are described, all occurring following post-partum haemorrhage.

It is suggested that a careful clinical history and examination by a physician who is aware of the comparative frequency and the vagaries of the syndrome should reveal the diagnosis.

Special attention should be directed to the facial appearance, which is smooth, pale and waxy, leading to a mistaken impression of a severe anaemia. This is disproved by the blood count. This appearance and the absence or scantiness of axillary and pubic hair are striking. There is depression of all vital functions. The pulse is small and feeble and there is hypotension.

Of the special investigations, a. low basal metabolic rate and a high serum cholesterol indicate a secondary thyroid deficiency. The remarkable rise in serum cholesterol to $743 \mathrm{mgm}$. per cent. in Case 3 illustrates this well, being possibly a reaction to the sudden withdrawal of thyroid. It is noted that this high reading was not accompanied by other evidence of increasing myxoedema.

The ketosteroids were only really low in Case 2, almost normal in Cases 3 and 4. The eosinophil test has been used in Cases 3 and 4 with expected results; it should, however, be noted that this 
test gives no indication whether the deficiency is primarily pituitary or suprarenal.

The insulin sensitivity test was helpful in Cases 3 and 4 . This test is not without risk, even with the smaller testing dose, and adequate preparation to have adrenaline and glucose by the bedside to deal with the hypoglycaemic state are essential. If the blood pressure is low before the test (as in Case 3) quarter-hourly readings should be taken, and the test should be discontinued if either the systolic blood pressure falls to $50 \mathrm{~mm}$. $\mathrm{Hg}$ or below, or if the patient cannot be roused.

The results of treatment are difficult to assess. It seems that some of these cases are sensitive even to small doses of thyroid (as in Case 3), and the optimum dose has to be discovered by clinical observation, preferably in hospital, rather than as an out-patient, with the risk of inducing an adrenal crisis.
Very small doses of thyroid, together with methyl testosterone, appear to have been of benefit in Cases 2 and 3, and are being used in Case 4. Much of the improvement is subjective and in none of the cases was there new hair growth or $\stackrel{5}{\mathcal{D}}$ recurrence of menarche. That subjective state of $\bar{\tau}$ well-being and new energy, accompanied objectively by agility and the ability to do a day's work and to enjoy it, as related by patient and witnessed by relatives, puts the whole problem of hypopituitarism on a more than merely academic plane, and make the physician's efforts well worth while.

My thanks are due to Dr. R. Sleigh Johnson, under whom Cases I, 2 and 3 were admitted, and to Dr. T. Rowland Hill for Case 4, for permission to publish these notes. Also to Drs. Thomas and Williams of the Department of Pathology for advice and help readily given.

\section{BIBLIOGRAPHY}

FRAZER, RUSSELL, and SMITH, PATRICIA H. (194I), Quart. F. Med., 34 (N.S. IO), 297.

SHEEHAN, H. L., and SUMMERS, V. K. (1949), Quart. F. Mea., I8, 3 19.

SIMMONDS, M. (1914), Virchow's Arch., 217, 226.

THORN, G. W. (1040), 'Diagnosis and Treatment of Adrenal

Insufficiency.' Oxford: Blackwell.

\section{CLINICAL SECTION}

\section{CLINICO-PATHOLOGICAL CONFERENCE - No: 7 *}

\section{Sarcoidosis with Lung Cavitation}

\section{Clinical History (Dr. J. G. Scadding)}

The case we have to consider today is that of a housewife who was aged $4 \mathrm{I}$ at the time of her death $\uparrow$.

In the family history there was nothing relevant to her illness, and she knew of no contact with cases of tuberculosis. She had had three pregnancies, of which the first was in 1940 with a difficult labour, the child dying at the age of 8 days with convulsions; the second was in 1943 and the

\footnotetext{
*Held at the Postgraduate Medical School (Hammersmith Hospital) on June 21, 1950. The report was assembled by Dr. Bernard Lennox. The photographs are by Mr. E. V. Willmott and Mr. K. G. Moreman.

†The clinical history of this case up to November 1949 has been briefly described by Scadding (r950), Brit. Med. F., I, 745 (Case I6).
}

child is well; the third in 1946 was complicated by a retained placenta and haemorrhage, which necessitated manual removal of the placenta under anaesthesia, and blood transfusion. The child is well. She appears to have had no other serious illness previously.

Her illness started insidiously after the birth of the third child and the complications already noted. She thought that she had never felt well since then, but no definite symptoms developed until June 1947, when she noticed pains in the joints, chiefly the fingers, the wrists, the elbows, the shoulders, the jaw, the hips and the knees. In February 1948 she had an acute febrile illness diagnosed as broncho-pneumonia and was in bed for two weeks with this. Her cough appears to date from this illness, but it was not until July 1948 that it became troublesome with expectora- 